Role of agricultural engineering in environmental and sustainable development for the valley and delta areas: 1420 - 1433

\title{
EVAPORATIVE COOLING AND TEMPERATURE INSIDE GREENHOUSE UNDER HOT ARID AIR CONDITIONS
}

\author{
*Abdel-Rahman, G.M and **Al-Amoudi A. O
}

\section{ABSTRACT}

The aim of the present work is to study the effect of evaporative cooling system for greenhouse under humid and hot weather. A gable roof design greenhouse was covered with old fiberglass glazing for more than 15 years was used. The experiment was carried out for 26 days of continuous data measuring, starting from June 8 to July 3 of year 2010 where the highest outside air temperature was obtained. Greenhouse dimension was $24 \mathrm{~m}$. long, $10 \mathrm{~m}$. width and $4 \mathrm{~m}$. height. The results show that the highest difference of about 10-11 ${ }^{\circ} \mathrm{C}$. was between cooling pad section and outside air temperature. Meanwhile, the lowest temperature differences were 2-6 ${ }^{\circ} \mathrm{C}$. between middle section of the greenhouse and cooling pad section. The maximum value of sensible heat transfer was 53 $\mathrm{kJ} / \mathrm{s}$ between outside and evaporative pad.

\section{INTRODUCTION}

The aim of this research work is to study the effect of evaporative pad of evaporative cooling system for greenhouse under humid 1 and hot weather. This research was conducted in Hada El-Sham Agricultural Research Station; Faculty of Meteorology, Environment and Arid Lands Agriculture, King Abdulaziz University, Jeddah, KSA. One agricultural novel for dew point evaporative cooling has been experimentally introduced by Riangvilaikul and Kumar (2010) It was constructed and experimented to investigate the outlet air and the system effectiveness at different inlet air conditions (temperature, humidity and velocity) covering dry, temperate and humid climates.

\footnotetext{
* Associate Professor, Agr. Eng. Dept., Fac. Agri. Cairo Uni. Cairo, Egypt; currently loaned to the Fac. of

Meteorology, Environment and Arid Land Agriculture. KAU, Jeddah, KSA

** Associate Professor, Fac. Of Meteorology, Environment and Arid Land Agriculture. KAU, Jeddah, KSA
} 
The results showed that wet bulb effectiveness ranged between 92 and $114 \%$ compared to dew point effectiveness between 58 and $84 \%$. At inlet air temperature more than $30{ }^{\circ} \mathrm{C}$., the velocity of intake air should be kept below $2.5 \mathrm{~m} / \mathrm{s}$ to obtain wet bulb effectiveness greater than $100 \%$. The dry and wet bulb effectiveness did not vary much during continuous operation under real ambient condition. This indicates the potential of this system for air conditioning applications. For hot and dry climate application, this system alone can provide comfort condition at inlet temperature and humidity ratio less than $45{ }^{\circ} \mathrm{C}$ and $11.2 \mathrm{~g} / \mathrm{kg}$, respectively. Whereas, Dilip (2007) modified evaporative cooler named two-stage evaporative cooler (TSEC) to improve the efficiency of evaporative cooling for high humidity and low temperature air conditioning for fruits and vegetable storage room. Two-stage evaporative cooler consists of the heat exchanger and two evaporative cooling chambers. The performance of cooler has been evaluated in terms of temperature drop, efficiency of the evaporative cooling and effectiveness of TSEC over single evaporation. The temperature drop through TSEC ranged from 8 to $16{ }^{\circ} \mathrm{C}$. While efficiency of single evaporation was 85-90\%. Effectiveness of the two-stage evaporative cooling was found to be 1.1-1.2 time over single evaporation. Kumar et Al. (2009) introduced a comprehensive review on the design and technology for cooling of greenhouse during summer months. Effect of characteristic design parameters on greenhouse microclimate and the applicable cooling technologies have been discussed. Fan and pad system is best suitable in the areas of low humidity of tropics and subtropics as inside air temperature can be lowered between $4-6{ }^{\circ} \mathrm{C}$ if used alone and $4-12{ }^{\circ} \mathrm{C}$ if used along with shading. Fog/mist system is suitable in peak summer to reduce the unwanted internal greenhouse temperature by 3-8 ${ }^{\circ} \mathrm{C}$ as compared to ambient condition. Based on the review, salient areas in need of further research are focused. Ashish et al. (2008) applied a thermal model to predict the air temperature in a cascade greenhouse. The fan-pad system has been used for evaporative cooling and an inner thermal curtain has been used to divide the greenhouse in two zones. Experiments have been conducted in hot summer conditions at Solar Energy Park, IIT Delhi, New Delhi, India for empty greenhouse. The 
results showed that the use of evaporative cooling with a thermal curtain reduces the temperature of greenhouse by 5 to $8{ }^{\circ} \mathrm{C}$. in the second zone of greenhouse in comparison to greenhouse without curtain in May. Maerefat and Haghighi (2010) studied a low-energy-consumption technique to enhance passive cooling and natural ventilation and an Evaporative Cooling Cavity (ECC). To determine the heat and mass transfer characteristics of the system, a mathematical model based on conservation equations of mass and energy has been developed and solved by an iterative method. The results show that when the relative humidity is lower than $50 \%$, the system can make good indoor air condition even at $40{ }^{\circ} \mathrm{C}$, and a higher performance is achieved using ECC. It is found that the proposed system may be applied successfully in hot arid climates to fulfill the indoor thermal comfort expectations. Ganguly and Ghosh (2007) tried to apply greenhouse technology in the field of floriculture is rapidly expanding worldwide. For greenhouses in hot, and humid summer climates, cooling and ventilation are major factors influencing the production of quality flowers. Thermal performance of the greenhouse, as predicted by the model under different climatic conditions is analyzed and compared with a reference study available in the literature. The analysis reveals that a suitable combination of evaporative cooling, shading and ventilation arrangements can effectively maintain the inside microclimate of the greenhouse within permissible limits throughout the year. Additionally, Metin et al. (2009) stated that the temperatures in Mediterranean regions frequently exceed $30{ }^{\circ} \mathrm{C}$ for long periods during summers. Pad evaporative cooling systems may provide a solution for controlling the high temperatures that can negatively affect poultry houses. This research, aiming to investigate the performance characteristics of evaporative pad cooling systems for the Mediterranean region of Turkey, was carried out in a typical poultry house from 18 July to 3 August 2006. Average evaporative cooling efficiency ranged from 69 to $72 \%$ through July to beginning of August. Temperature decreased in pad exit during the experiment from 4.4 to $7.3{ }^{\circ} \mathrm{C}$. Chung and Chiu (2002) studied two alternative materials including one made of coarse fabric PVC sponge mesh $2.5 \mathrm{~mm}$ diameter in pinhole and one made of fabric PVC sponge 
mesh in $7.5 \mathrm{~mm}$ diameter pinhole were tested as pads in wind tunnel experiment. The procedure used in this study allows accurate determination of evaporative cooling performance in terms of evaporative cooling efficiency and static pressure drop. Cooling efficiencies for coarse fabric PVC sponge ranged from 63.88. 81.10 and $86.75 \%$ respectively, for 50,100 , and $150 \mathrm{~mm}$ thickness under normal operating air velocities of 1.0-1:5 m s-1. Cooling efficiencies for fine fabric PVC sponge ranged from 47.22, $72.25 \%$, and $85.51 \%$ for 50,100 , and $150 \mathrm{~mm}$ thickness, respectively, under normal operating air velocities. Results of this study will be used to determine operating protocols for future tests investigating criteria. Sethi and Sharma (2007) concluded the available worldwide review of cooling technologies for agricultural greenhouses and discussed the representative applications of each technology. Relevant information about the system characteristics, application and performance of the existing greenhouse cooling technologies, such as; ventilation (natural and forced), shading/reflection, evaporative cooling (fan-pad, mist/fog and roof cooling) and composite systems (earth-to-air heat exchanger system and aquifer coupled cavity flow heat exchanger system) is collected and presented in detail. Finally, it can be concluded than none of the currently available technologies is perfect which can meet all the cooling requirements of the greenhouse and inside crops. The selection and operation of the system is based on various parameters such as type of climate, crop to be grown, cost, maintenance, ease of operation, reliability, life of the system, dependency on electricity, etc. So the most suitable technology for greenhouse cooling is that which meets most of the desired conditions of the farmer to grow offseason crops in order to fetch maximum returns. Naticchia et al. (2010) studied the summer conditioning consumption becoming a tough and critical issue, consequently there is a need to provide buildings with new technologies for energy saving. This solution basically suggests equipping standard ventilation with a proper water-evaporative system, which exploits the latent heat of water evaporation, in order to absorb summer cooling loads. The insulation will act not only as a standard insulating material, but also as a porous surface to store water sprayed by the system and then 
gradually release it when needed for cooling. The experimental analyses showed the effectiveness of this technology, which decreases the overall summer energy load in buildings by canceling conduction loads.

\section{MATERIAL AND METHODS}

The present work is aimed to study the effect of evaporative cooling system for greenhouse under humid and hot weather. The experiment was carried out for 26 days starting from June 8 to July 3 of year 2010 where the highest outside air temperature is obtained. This research was conducted at one of the greenhouse of Hada El-Sham farm, considered as the agricultural research station of the Faculty of Meteorology, Environment and Arid Lands Agriculture, King Abdulaziz University, Jeddah, KSA.

\section{1 - Greenhouse specifications}

The selected greenhouse is of gable roof design, covered with old fiberglass glazing (more than 15 years old). Greenhouse dimensions are $24 \mathrm{~m}$. long, $10 \mathrm{~m}$. width and $4 \mathrm{~m}$. height.

\subsection{Cooling system specifications;}

3.2.1 Evaporative cooling pad was installed in one end of the greenhouse with $8 \mathrm{~m}$ length; fully covered excluding side door, $1.4 \mathrm{~m}$ height and $0.1 \mathrm{~m}$. thickness. On the opposite end of the greenhouse, there were 2 exhaust electrical fans with diameter of $1.4 \mathrm{~m}$. with 400 rpm.

3.2.2. All sensors (air temperature sensors and relative humidity sensor) were tested and calibrated under the experiment's circumstances before data were collected. The CR3000 logger with 4-MB memory can be expanded with add-on memory systems. Program with LoggerNet, Supports Modbus protocol, SDI-12 protocol, and SDM devices. Logger scanned all sensors every 30 minutes and recorded the data. Temperatures were measured along the greenhouse at three different positions $2 \mathrm{~m}$ away from evaporative pad, $10 \mathrm{~m}$ from the first sensor (right in the middle of the greenhouse) and $10 \mathrm{~m}$ from the second sensor ( $2 \mathrm{~m}$ before exhaust fan). Meanwhile relative humidity sensor 
was hung $2.5 \mathrm{~m}$ above the soil surface. All sensors were connected to Campbell- scientific Data- - logger CR3000 .

3.2.3 Evaporative cooling system.

In the compartment used for the experiment, an evaporative pad made of corrugated cardboard covered the southern wall opening. Two electric exhaust window fans $0.75 \mathrm{~m}$ in diameter, each with a rated outflow of $16,000 \mathrm{~m}^{3} / \mathrm{h}$ at zero static pressure, were mounted on north gable. The evaporative pad and the fans were turned on, when the air temperature in the greenhouse exceeded $28 \mathrm{oC}$ and off when air temperature dropped below $268 \mathrm{C}$. When in operation, about $90 \%$ of the pad surface was wet.

\section{5- Mathematical Analysis:-}

In order to clarify the concept of forced convection of heat and mass transfer, a steady state solution was presumed to justify the forced convection heat and mass transfer. The cold air coming from the evaporative cooler, gradually heats up through the greenhouse due to incident. Abdel-Rahman (2005) introduced a series of equations to approach computing the steady state heat and mass transfer equations:-

$$
\mathbf{Q}_{\mathrm{se}}=\mathbf{V} \rho_{\mathrm{air}} \mathbf{C}_{\mathbf{p}}\left(\mathbf{T}_{\mathbf{o}}-\mathbf{T}_{\mathbf{i}}\right)
$$

Where:

$\mathrm{Q}_{\mathrm{se}} \quad$ heat released from the incoming air

$(\mathrm{kJ} / \mathrm{s})$

$\mathrm{V} \quad$ incoming air velocity

$\rho_{\text {air }} \quad$ air density (1.127) at $40{ }^{\circ} \mathrm{C}$.

$\mathrm{C}_{\mathrm{p}} \quad$ specific heat at constant pressure (1.005)

$\left(\mathrm{kg} / \mathrm{m}^{3}\right)$

$\mathbf{T}_{\mathbf{o}} \& \mathbf{T}_{\mathbf{i}} \quad$ Out and inside greenhouse air temperature respect.

$$
\mathbf{V}=\mathbf{C}_{\mathbf{d}} A \mathbf{N}_{\mathbf{p}} \mathbf{U}_{\text {air }}
$$

Where:

$\mathrm{C}_{\mathrm{d}} \quad$ discharge coefficient dimensionless

$\begin{array}{ll}A & \text { cooling opening area } \\ N_{p} & \text { number of cooling openings, dimensionless } \\ U_{\text {air }} & \text { incoming cooling air velocity. }\end{array}$

$(\mathrm{m} / \mathrm{s})$ 
The sensible and latent heat transfer of the air stream as a function of time from the cooling pad throughout the entire greenhouse length can be computed using the following equations:-

$$
\mathbf{Q}_{\text {se1 }}=\left(\mathbf{V} / \mathbf{A}_{\mathrm{g}}\right) \rho_{\text {air }} \mathbf{C}_{\text {pair }}\left(\mathbf{T}_{\mathbf{m}}-\mathbf{T}_{\mathbf{p}}\right)
$$

This is for the first half of the greenhouse (from the cooling pad " $\mathrm{T}_{\mathrm{p}}$ " to the middle of the greenhouse " $\mathrm{T}_{\mathrm{m}}$ "), on the other hand from the middle to the fan suction (last section) " $\mathrm{T}_{\mathrm{f}}$ " can be calculated from the following equation :-

$$
\mathbf{Q}_{\mathrm{se} 2}=\left(\mathbf{V} / \mathbf{A}_{\mathrm{g}}\right) \rho_{\text {air }} \mathbf{C}_{\text {pair }}\left(\mathbf{T}_{\mathrm{f}}-\mathbf{T}_{\mathrm{m}}\right)
$$

Where:

$\begin{array}{lll}\mathrm{A}_{\mathrm{g}} & \text { ground surface area of the greenhouse } & \left(\mathrm{m}^{2}\right) \\ \rho_{\text {air }} & \text { air density } & \left(\mathrm{kg} / \mathrm{m}^{3}\right) \\ \mathrm{C}_{\text {pair }} & \text { specific heat of air at constant pressure } & (\mathrm{J} / \mathrm{kg} . \mathrm{K})\end{array}$

\section{RESULTS AND DISCUSSIONS}

The results of the present cover four main parts as follows; Air temperature profile along the greenhouse (cool pad, middle and fan). Also, air temperature difference between cooling pad versus outside, plus air temperature of both new and old pad versus outside relative humidity were include. Added to air temperature, differences between cooling pad and outside versus relative humidity.

\section{4-1 Air temperature profile along the greenhouse (cool pad, middle and fan).}

It was obvious from figure (1) that the temperature profile along the greenhouse shown that. There is a harmony between air temperature profile inside and outside greenhouse along the entire experiment period. The highest difference (about $10-11{ }^{\circ} \mathrm{C}$ ) between cooling pad section and outside air temperature was recorded in June 20. It is obvious that there is a trivial difference (less than $1{ }^{\circ} \mathrm{C}$.) between air temperature profiles of middle (mid) and end section of the greenhouse (fan) as shown in figure (1) along the entire experiment period. Meanwhile, there was about 


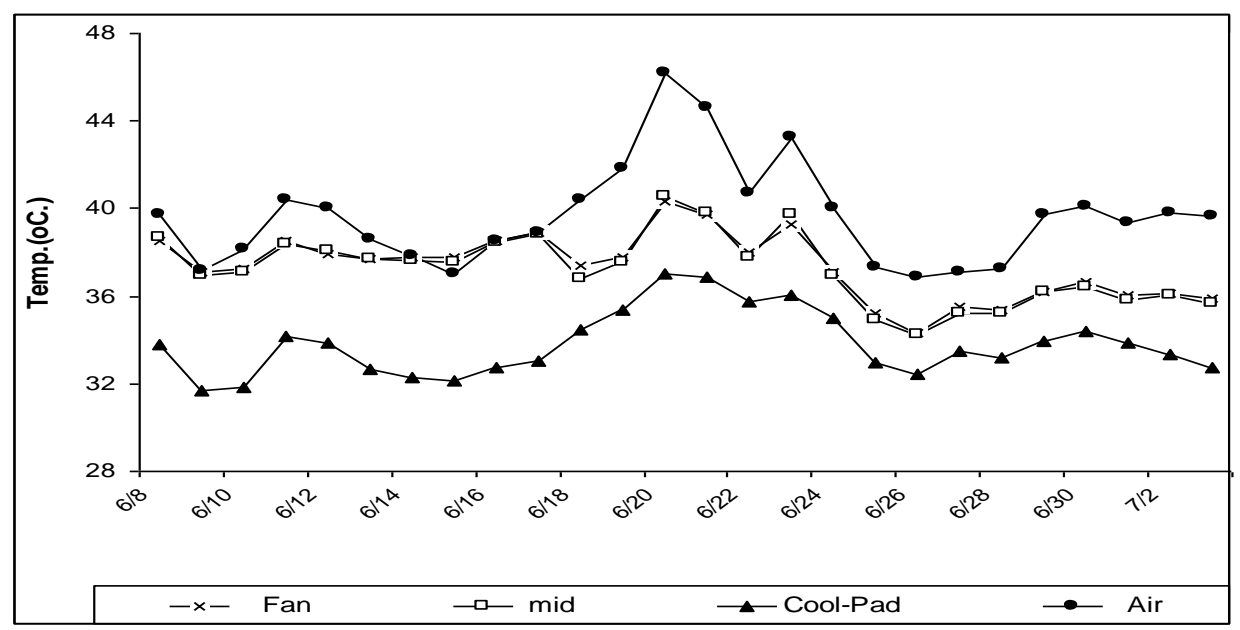

Figure (1) Air temperature profile inside and outside the greenhouse. 2-6 ${ }^{\circ} \mathrm{C}$. between middle section of the greenhouse and cooling pad section along the entire experiment period.

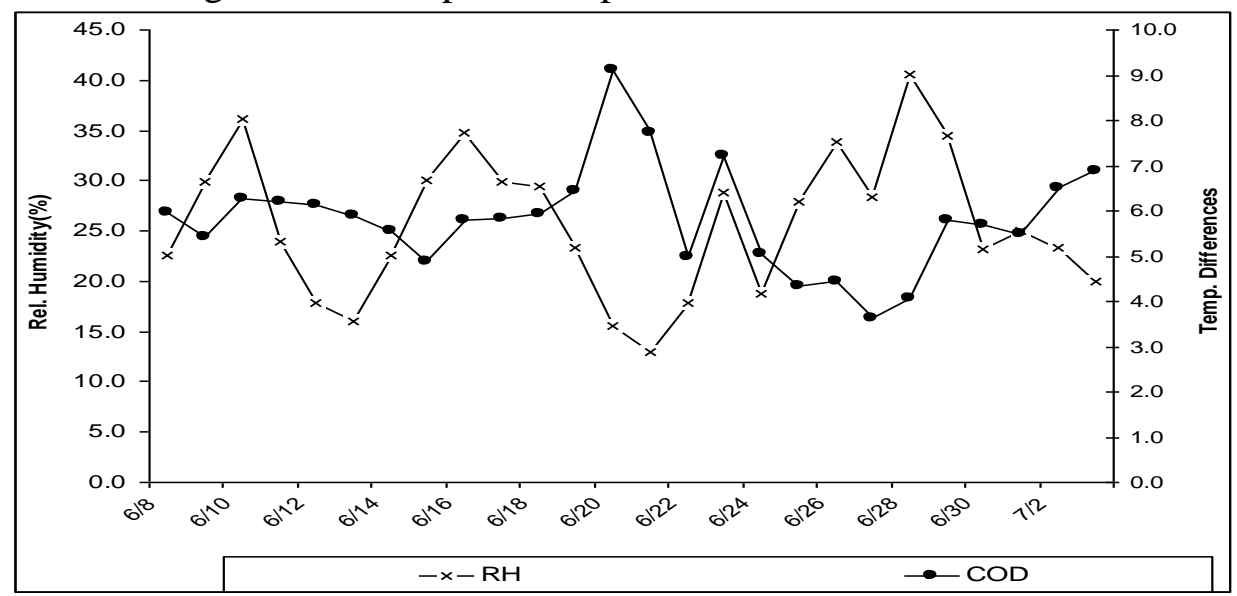

Figure (2) Air relative humidity and air temperature of COD

Figure (2) shows an important relationship between outside relative humidity and difference between air temperature of cooling pad versus outside greenhouse abbreviated as (COD). It is noticeable that the highest value of COD was (10-9 ${ }^{\circ} \mathrm{C}$.) and lowest value of outside relative humidity was (12\%), those were recorded around the day of 20-21 June. 


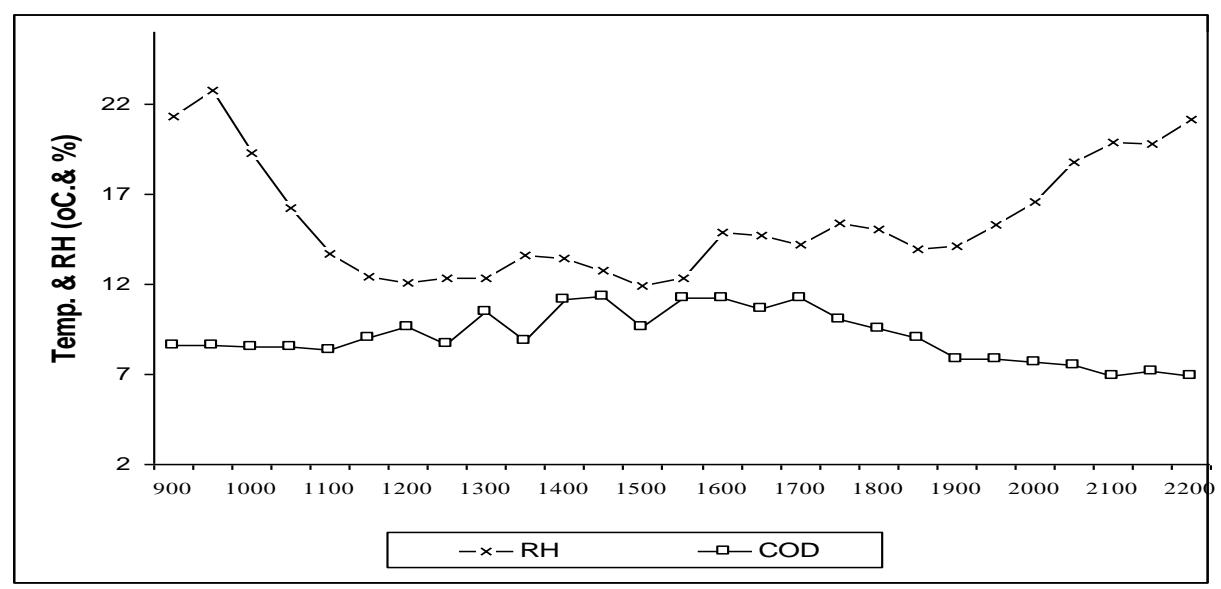

Fig. (3) Highest value of COD versus outside rel. humidity recorded in 20 June

The highest value of COD was recorded around 3 and $4 \mathrm{pm}$. Simultaneously relative humidity recorded the lowest value about $12 \%$ as shown in figure (3). On the other hand the lowest COD value $\left(6{ }^{\circ} \mathrm{C}\right.$.) corresponding to the highest relative humidity of $(22 \%)$ were recorded earlier in at 9 am and later at 10 pm respectively.

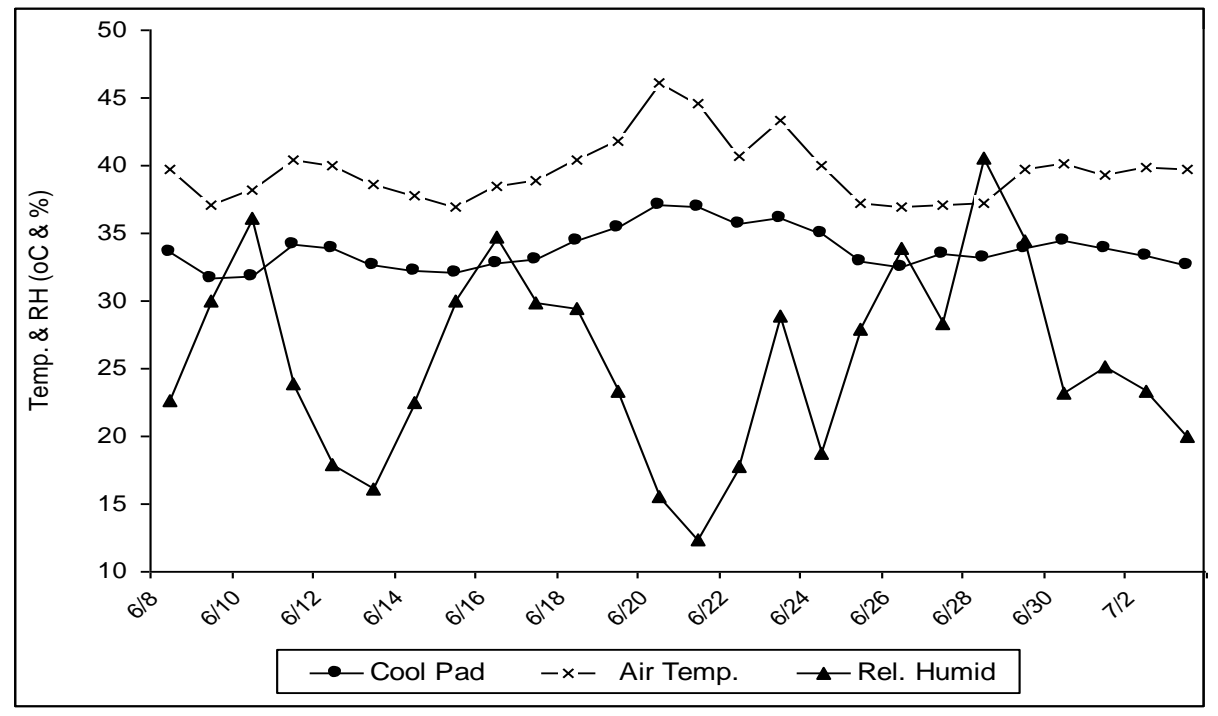

Fig. (4) Air cooling pad temperature versus outside rel. humidity

Air relative humidity recorded the lowest value between June 20 and 21 as about $12 \%$ along the entire experiment period. Meanwhile the 
highest air temperature average was obtained in June 20 to ensure the indirect relationship between air temperature and relative humidity.

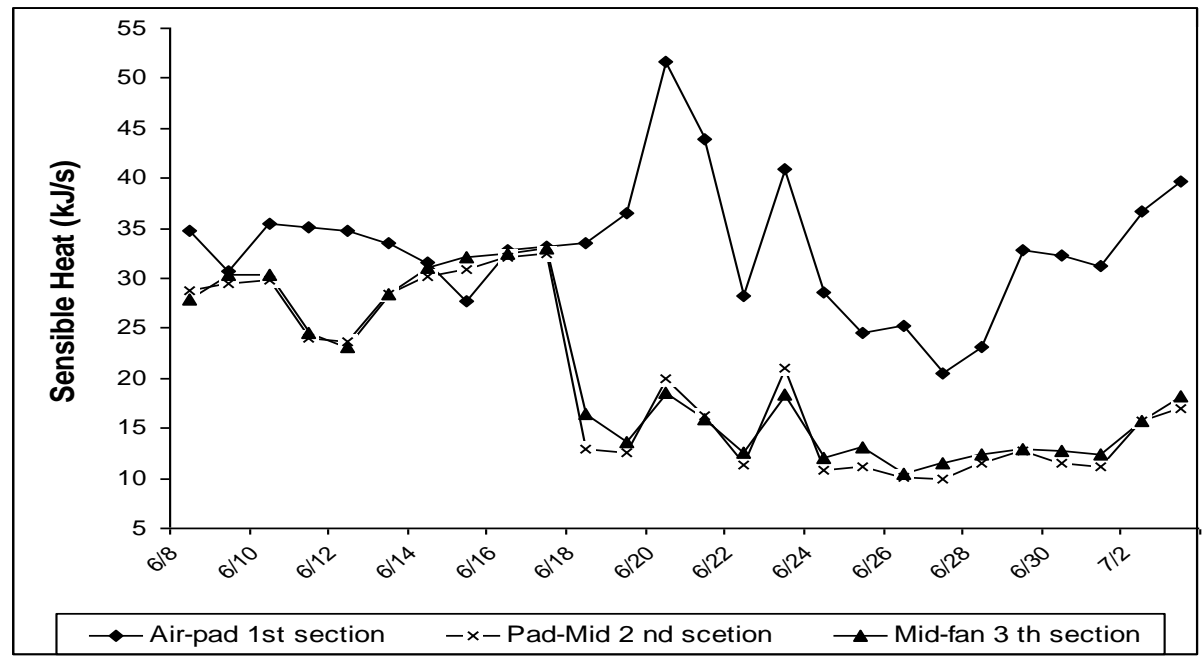

Fig. (5) Sensible heat transfer through the greenhouse sections.

\section{4-2 Sensible heat transfer along the greenhouse (cool pad, middle and fan).}

Sensible heat transfer was highly recognized between first section of the greenhouse (cooling pad) and both middle and end section (fan) of the greenhouse for the entire experiment period. Heat transfer reached the maximum value of $53 \mathrm{~kJ} / \mathrm{s}$ in June 20 . It was very noticeable that there was a gap between first section (between outside air and pad), and both second and third sections. This gap was recognized from June 18 till the end of the experiment July 3. This is due to the increasing of heat stress where the air temperature jumped from end of thirties to the upper limit of forties centigrade. Consequently, the highest sensible heat transfer value was obtained around June 20 to 21 above $53 \mathrm{~kJ} / \mathrm{s}$ between outside air temperature and cooling pad. Meanwhile there was clear harmonic fluctuation between sensible heat transfer cooling pad and middle section and also between middle section and end section (fan) of the greenhouse. The lowest value obtained of sensible heat transfer recorded between cooling pad and middle section was $10 \mathrm{~kJ} / \mathrm{s}$. 


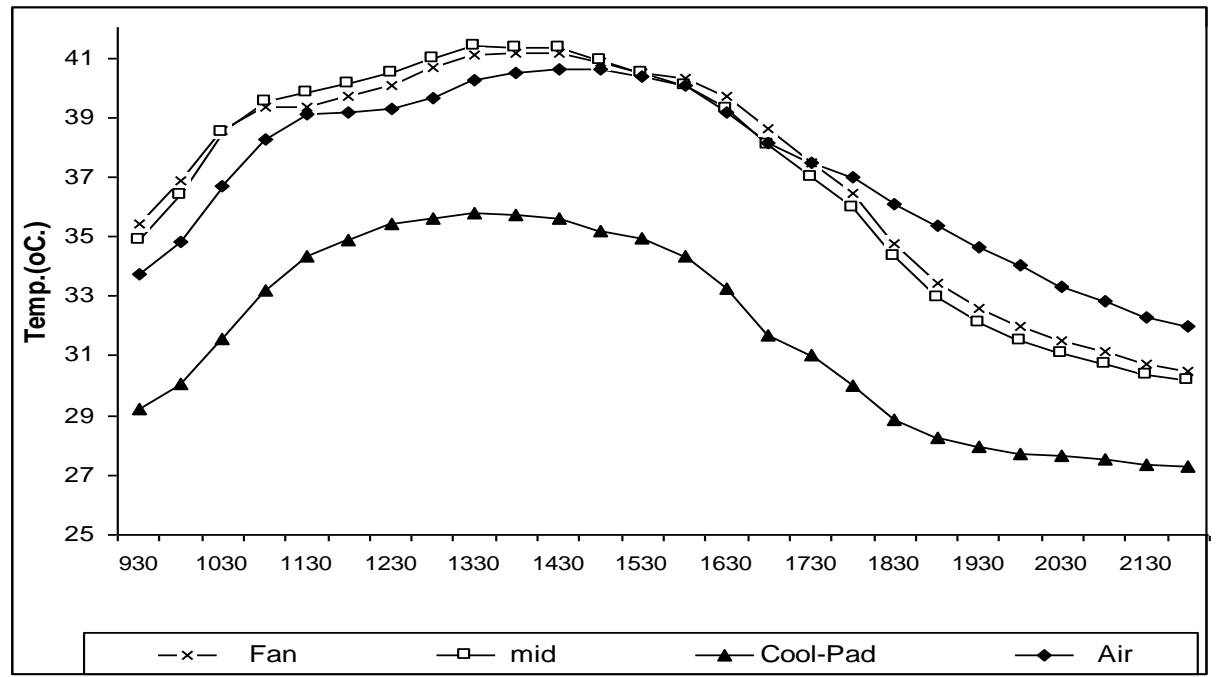

Fig. (6) Greenhouse lowest air temp. distribution profile in 9 June

The lowest air temperature obtained was in June 9 where the lower value by the end of the day was $28,30,31$ and $32{ }^{\circ} \mathrm{C}$. for cooling pad, middle, end section (fan) and outside respectively later at $10 \mathrm{pm}$ evening as shown in figure 6 . Meanwhile in the mid-day time (at $2 \mathrm{pm}$ ) these values were $35,39,40$ and $41^{\circ} \mathrm{C}$. for cooling pad, middle, end section (fan) and outside respectively.

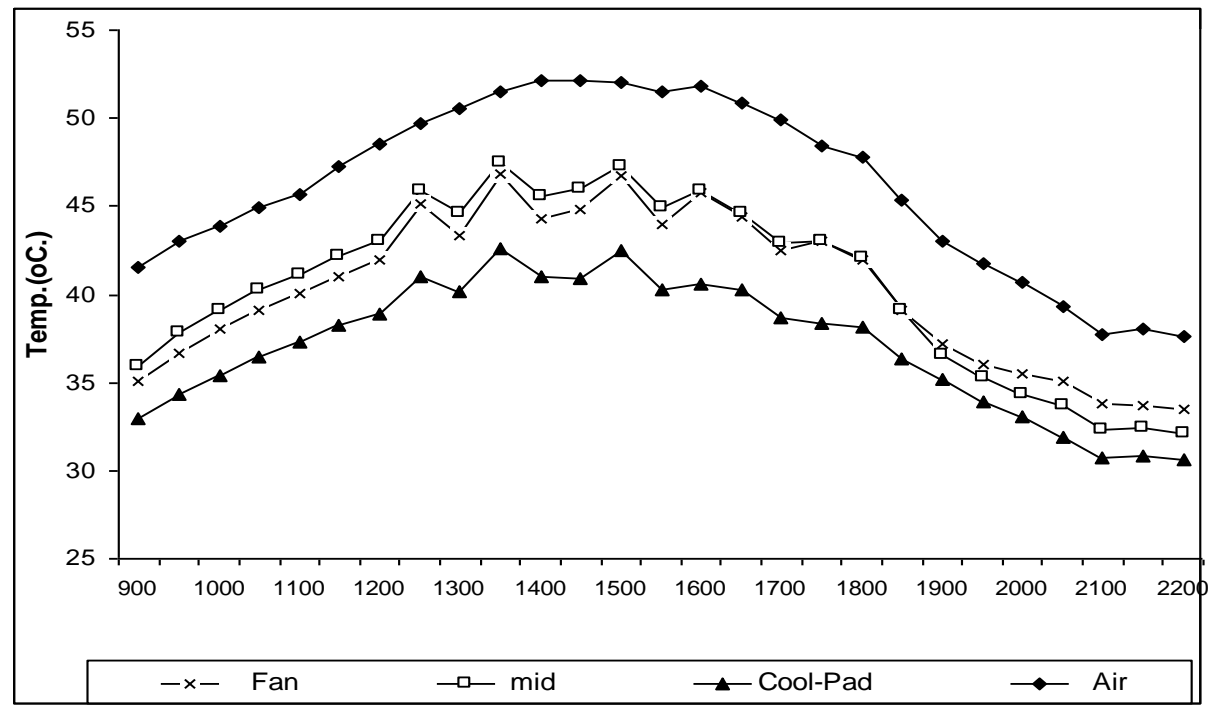

Fig. (7) Greenhouse highest air temp. distribution profile in 20 June 
On the other hand, the hottest day throughout the experimental period was June 20 as it shown in figure 7 , where the outside temperature reached about $54{ }^{\circ} \mathrm{C}$. between $3-4 \mathrm{pm}$ at the sometime cooling pad temperature recorded the highest value at $42{ }^{\circ} \mathrm{C}$. Meanwhile the lowest temperature recorded for cooling pad was $31{ }^{\circ} \mathrm{C}$. at $10 \mathrm{pm}$ in the evening, whereas outside air temperature was $39^{\circ} \mathrm{C}$. respectively.

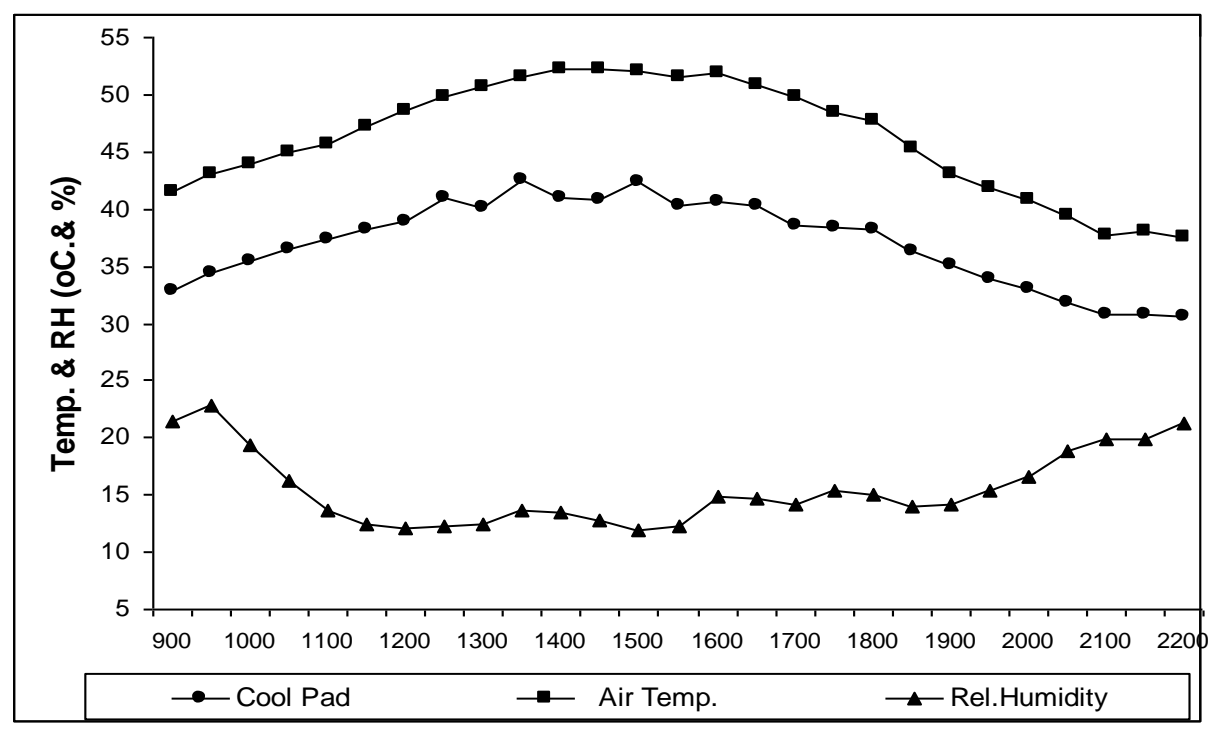

Fig. (8) Cooling pad, air temp. and rel. humidity profile along greenhouse in 20 June.

The cooling pad accomplishes air temperature reduction of about 10-11 ${ }^{\circ} \mathrm{C}$. below the outside temperature during the hottest day of June 20 as shown in figure 8 . This temperature difference was very noticeable along the entire effective period of the day from 9 am to $10 \mathrm{pm}$. Meanwhile, the indirect relationship between outside air temperature and cooling pad temperature versus relative humidity is clearly noticeable in figure 8 .

\section{SUMMARY AND CONCLUSION}

The present work is aimed to study the effect of evaporative cooling system for greenhouse under dry and hot weather. The experiment was carried out -after calibrating all the used sensors- for 26 days starting from June 8 to July 3 of year 2010. This research was conducted at one of the greenhouses of Hada El-Sham farm considered as the Agricultural Research Station of the Faculty of Meteorology, Environment and Arid Lands Agriculture, King Abdulaziz University, Jeddah, KSA. The 
experimental greenhouse was divided into three sections, first (between outside air and cooling pad), second (between cooling pad and middle of the greenhouse) and third (between middle and end or fan). The results showed that the highest difference of about $10-11{ }^{\circ} \mathrm{C}$. between cooling pad section and outside air temperature. Meanwhile, the lowest temperature differences were $2-6{ }^{\circ} \mathrm{C}$. between middle section of the greenhouse and cooling pad section. The maximum value of sensible heat transfer was $53 \mathrm{~kJ} / \mathrm{s}$ between outside and evaporative pad.

\section{REFERENCES}

Abdel-Rahman, G. M. 2005. Air temperature distribution along two greenhouses with different evaporative cooling materials. The 13th Ann. Confe. of Misr Soci. of Ag. Eng. : 23, (2), 167-179.

Ashish Shukla; G.N. Tiwari and M.S. Sodha (2008) "Experimental study of effect of an inner thermal curtain in evaporative cooling system of a cascade greenhouse" Solar Energy, 82, Issue 1,: 61-72

Chung-Min Liao and Kun-Hung Chiu (2002) "Wind tunnel modeling the system performance of alternative evaporative cooling pads in Taiwan region" Building and Environment, 37: 177-187

Dilip Jain (2007) "Development and testing of two-stage evaporative cooler" Building and Environment, 42: 2549-2554

Ganguly, A. and S. Ghosh (2007) "Modeling and analysis of a fan-pad ventilated floricultural greenhouse" Energy and Buildings, 39: 1092-1097

Kumar K.S.; K.N. Tiwari and Madan K. (2009) "Design and technology for greenhouse cooling in tropical and subtropical regions: A review Energy and Buildings 41: 1269-1275

Maerefat M. and A.P. Haghighi (2010) "Natural cooling of stand-alone houses using solar chimney and evaporative cooling cavity Renewable Energy" 35: 2040-2052

Metin Dag tekina; Cengiz Karacab and Yilmaz Yildiz (2009) "Performance characteristics of a pad evaporative cooling system in 
a broiler house in a Mediterranean climate" Bio-systems engineering, 103: 100-104

Naticchia B.; M.D'Orazio; A.Carbonari and I.Persico (2010) "Energy performance evaluation of a novel evaporative cooling technique" 42: $1926-938$

Riangvilaikul, B. and Kumar, S. (2010) “An experimental study of a novel dew point evaporative cooling system" Energy and Buildings, 42: 637-644

Sethi V.P. and S.K. Sharma (2007) "Survey of cooling technologies for worldwide agricultural greenhouse applications" Solar Energy, 81: $1447-1459$

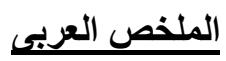

\section{التبريد التبخيرى وتوزيع حرارة الهواء داخل البيوت المحمية تحت ظروف الهواء الجاف الحار

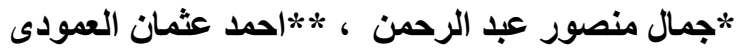

بهدف هذا البحث الى دراسة تأثير التبريد التبخيرى على تبريد البيوت المحمية تحت ظروف

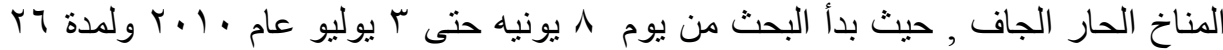

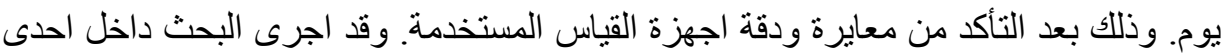

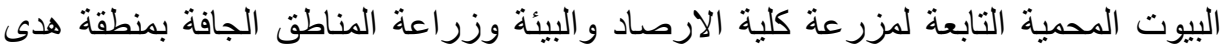

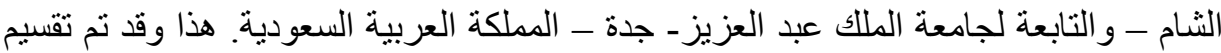

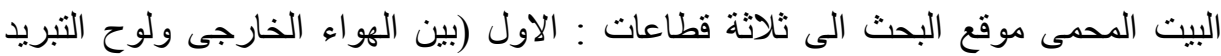

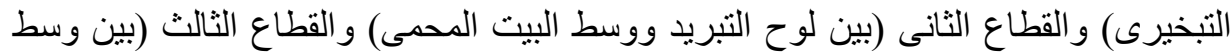

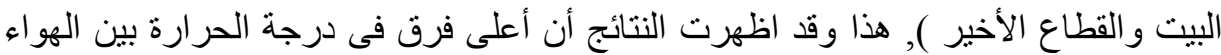

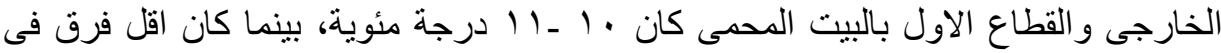

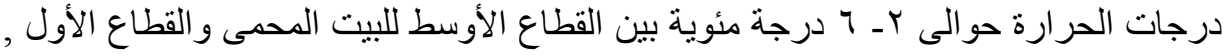

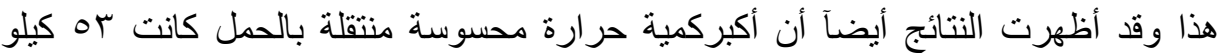
جول/ثانية، وقد تحققت بين القطاع الاول (لوح التبريد) و الهو اء الخارجى.

\footnotetext{
* أستذ مساعد - قسم الهندسة الزر اعية - زر اعة القاهرة - معار حالياً كأستاذ مشارك كلية الارصاد، البيئة

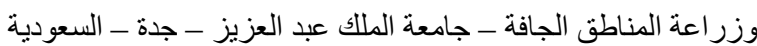
** أستاذ مشارك كلية الارصاد، البيئة وزر اعة المناطق الجافة - جامعة الملك عبد العزيز - جدة ـ السعودية
} 